\title{
Peroral cholangioscopy via an endoscopic ultrasound-guided hepaticojejunostomy route for distal bile duct cancer with Roux-en-Y reconstruction
}

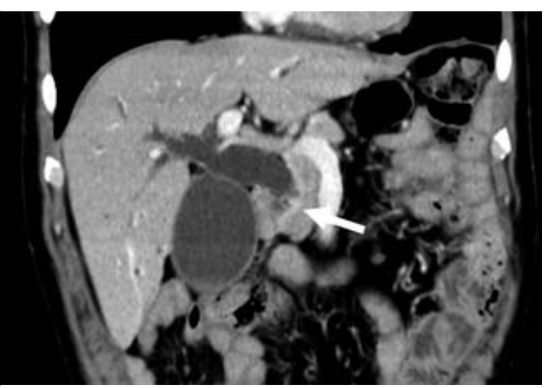

> Fig. 1 Contrast-enhanced computed tomography images of a stricture of the distal bile duct (arrow), with slight dilation of upstream bile duct and slight wall thickening of the hilar and intrahepatic bile ducts.

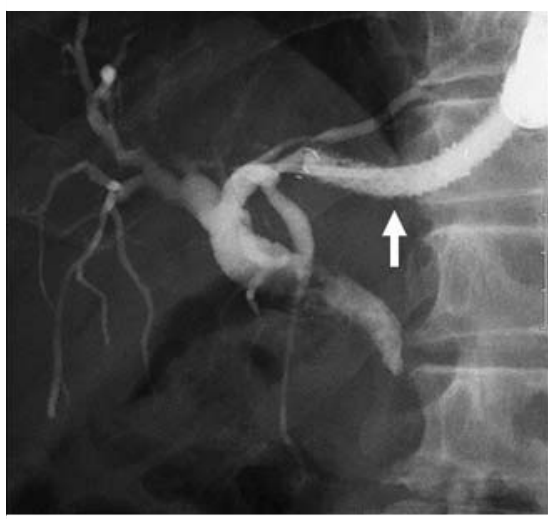

- Fig. 2 Endoscopic ultrasound-guided hepaticojejunostomy (EUS-HJS) was performed as the initial endoscopic procedure. The dilated intrahepatic bile duct was punctured via the jejunum using a 19-gauge needle (Expect; Boston Scientific Corp., Marlborough, Massachusetts, USA). An $8 \mathrm{~mm} / 8 \mathrm{~cm}$ fully covered self-expandable metallic stent (arrow; HANAROSTENT biliary; MI Tech, Gyeonggi-Do, Korea) was deployed across the EUS-HJS route.

A 70-year-old man who had undergone total gastrectomy with Roux-en-Y reconstruction was referred to our hospital with liver dysfunction. Imaging studies revealed a distal biliary stricture with dilated intrahepatic bile ducts ( $\mathbf{F i g . 1}$ ), indicating possible distal cholangiocar-

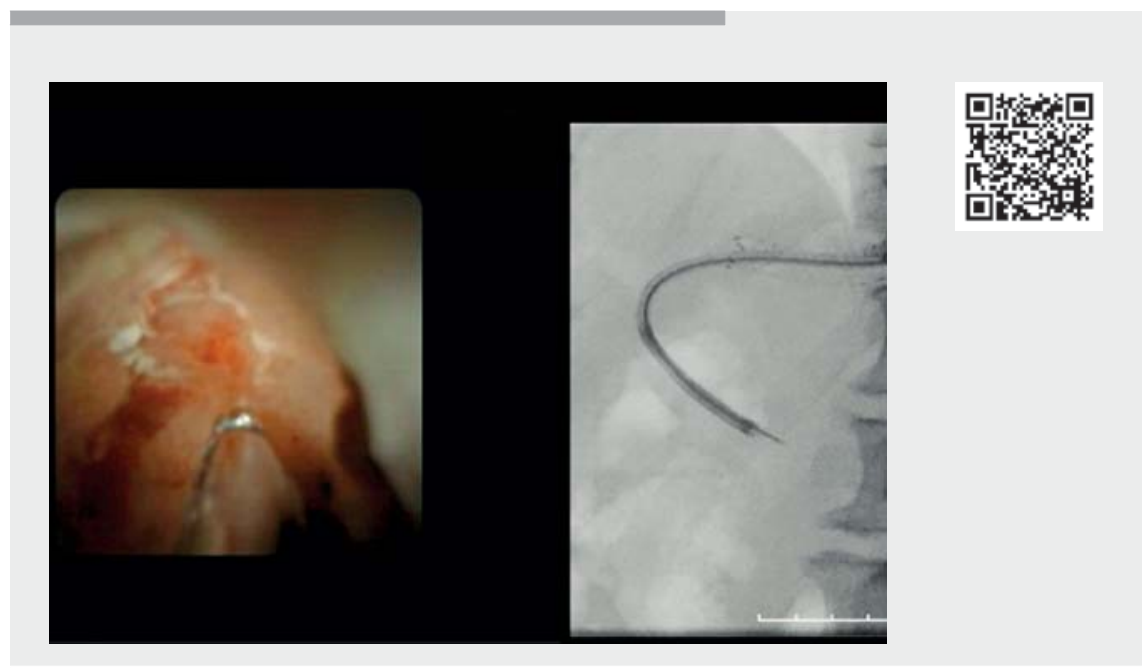

Video 1 Construction of an endoscopic ultrasound-guided hepaticojejunostomy route and subsequent peroral cholangioscopy for the determination of malignancy and extent of superficial spread.

cinoma. In order to perform peroral cholangioscopy to determine malignancy and extent of superficial spread, we planned to construct an endoscopic ultrasound-guided hepaticojejunostomy (EUS-HJS) route.

The dilated intrahepatic bile duct (B3) was punctured via the jejunum under EUS guidance using a 19-gauge needle (Expect; Boston Scientific Corp., Marlborough, Massachusetts, USA). An $8 \mathrm{~mm} /$ $8 \mathrm{~cm}$ fully covered self-expandable metallic stent (FCSEMS; HANAROSTENT biliary; MI Tech, Gyeonggi-Do, Korea) was then deployed across the EUS-HJS route after dilating it with a 7-Fr dilator (> Fig.2). After improvement in liver function, peroral cholangioscopy via the FCSEMS was carried out using the SpyGlass DS system (Boston Scientific Corp.) (\Video 1). Under cholangioscopic guidance, papillary mucosa with irregular vessels was mainly detected in the distal bile duct but not in the hilar and intrahepatic bile ducts (>Fig.3, > Fig.4, > Fig.5). In addition, we performed mapping biopsies using SpyBite forceps (Boston Scientific Corp.) in the distal, hilar, and intrahepatic bile ducts.

As adenocarcinomas were found only in the distal bile duct, the patient was scheduled to undergo pancreaticoduodenectomy. Histological findings of the resected specimens indicated that cholangiocarcinomas were located in the distal bile and cystic ducts. The FCSEMS deployed in the EUS-HJS route was endoscopically removed 30 days after surgery.

Although peroral cholangioscopy for patients with possible distal cholangiocarcinoma is effective for determination of malignancy and extent of superficial spread [1], the transpapillary approach is challenging to perform in patients with altered anatomies. Therefore, peroral cholangioscopy via an EUS-guided bilioenterostomy route [2] may be a useful alternative to the transpapillary approach for evaluating possible distal cholangiocarcinomas.

Endoscopy_UCTN_Code_TTT_1AS_2AD 


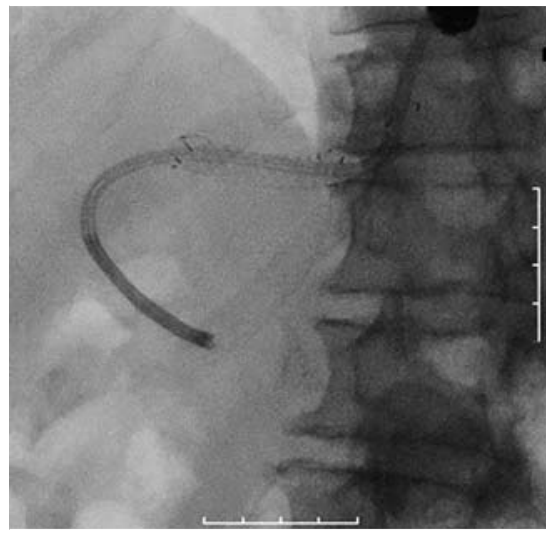

- Fig. 3 Fluoroscopic view of peroral cholangioscopy via an endoscopic ultrasound-guided hepaticojejunostomy (EUSHJS) route using a SpyGlass DS system (Boston Scientific Corp., Marlborough, Massachusetts, USA), which was advanced into the intrahepatic bile duct via the fully covered self-expandable metallic stent.

\section{Competing interests}

The authors declare that they have no conflict of interest.

The authors

Haruka Okano $९$ Shinsuke Koshita $९$ Yoshihide Kanno , Takahisa Ogawa , Hiroaki Kusunose, Toshitaka Sakai, Kei Ito

Public Interest Incorporated Foundation Sendai City Medical Center, Gastroenterology, Sendai, Japan

\section{Corresponding author}

\section{Haruka Okano, MD}

Department of Gastroenterology, Sendai City Medical Center, 5-22-1 Tsurugaya, Miyagino-ku, Sendai 983-0824, Japan haruka.o@openhp.or.jp

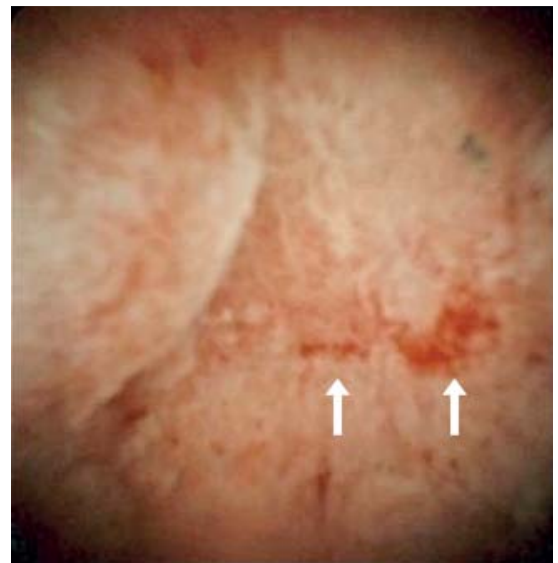

Fig. 4 Papillary mucosa with irregular vessels (arrows) was detected in the distal bile duct.

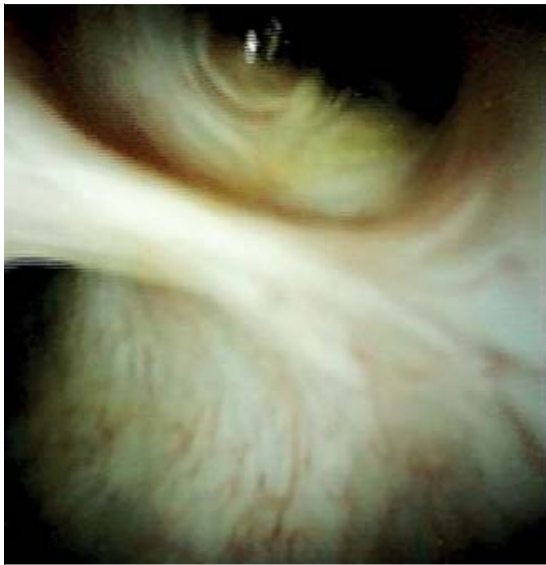

- Fig. 5 Cholangioscopic view of the bifurcation of anterior and posterior right hepatic ducts, showing no irregular vessels detected in the upstream bile duct.

\section{References}

[1] Ogawa T, Ito K, Koshita S et al. Usefulness of cholangioscopic-guided mapping biopsy using SpyGlass DS for preoperative evaluation of extrahepatic cholangiocarcinoma: a pilot study. Endosc Int Open 2018; 06: E199-E204

[2] Mukai S, Tsuchiya T, Itoi T et al. Endoscopic ultrasonography-guided hepaticogastrostomy with novel two-step puncture technique following peroral cholangioscopyassisted stone removal Dig Endosc 2020; 32 : e32-e33

\section{Bibliography}

Endoscopy 2022; 54: E188-E189

DOI 10.1055/a-1472-5683

ISSN 0013-726X

published online 12.5 .2021

(C) 2021. Thieme. All rights reserved. Georg Thieme Verlag KG, Rüdigerstraße 14, 70469 Stuttgart, Germany

\section{ENDOSCOPY E-VIDEOS}

https:/|eref.thieme.de/e-videos

口回回 Endoscopy E-Videos is an open access online section, 自辞: reporting on interesting cases and new techniques in gastroenterological endoscopy. All papers include a high quality video and all contributions are freely accessible online. Processing charges apply (currently EUR 375), discounts and wavers acc. to HINARI are available.

This section has its own submission website at

https://mc.manuscriptcentral.com/e-videos 